\title{
Orthopaedic training in Kenya
}

J. A. O. Mulimba, MBChB, MMed, FRCS, Associate Professor, Department of Orthopaedic Surgery, College of Health Sciences, University of Nairobi, P. O. Box 52507-00200, Nairobi, Kenya. Email: prof-jao@yahoo.co.ke

\section{ABSTRACT}

Background: Orthopaedic training in Kenya, like in other East, Central and Southern Africa college of surgeons (COSECSA) countries is varied leading to specialists with varying exposures and competencies. The experience in Kenya is used here to study the problem, point out the shortcomings and suggest possible remedies for the future.

Objective: To do a survey of the current orthopaedic specialists in Kenya's training since their first medical degrees. Determine the duration, facilities and methods of training.

Methods: A number of doctors trained under different arrangements were identified, interviewed and where curriculum was available this was read.

Results: The basic degree for most specialists was MMed (Surgery).This had six months of Orthopaedic Surgery. Post MMED exposure varied widely. The second group consisted of those with MMed or MSc. (Orthopaedics) of four years. Facilities, duration and methods of teaching varied widely.

Conclusions: The duration, facilities and methods of orthopaedic training varied widely in the region. The end products significantly differed in their practices and competencies, especially knowing that most of them go to work on their own after the training.

Recommendations: There is need to standardize the Orthopaedic training in the region. This could be best done through COSECSA. On its part COSECSA must strictly observe the training programme. The registering bodies must also draw up common criteria for Orthopaedic specialists' registration. Assistance from abroad in these early times is necessary.

\section{INTRODUCTION}

Orthopaedics in Kenya grew as an offshoot of surgery in 1972 when the department of orthopaedic surgery was created in the school of medicine at the University of Nairobi. The first orthopaedic surgeons were all foreigners and trained wherever they came from. They included Canadian, British, Indian, French and German trained surgeons. Much of the post graduate surgical training has been university based. There has been no formal postgraduate orthopaedic training programme in Kenya until recently. So how have the practicing 60 or so orthopaedic surgeons been trained. The basic medical training takes five academic years. In the $3^{\text {rd }}$ year students are introduced to orthopaedics and trauma for six weeks. In the fifth and final year the students do their final stint in orthopaedics composed of six weeks in clerkship and weekly lectures throughout the year. They then go into internship which includes six weeks rotation in orthopaedics and trauma. They then go to work as medical officers for two years, they are then eligible to apply for post graduate training in surgery or orthopaedics and orthopaedic trauma. Orthopaedics and trauma constitute one of the mandatory rotations in MMed(surg.) training. The students spend six months or three months each in two orthopaedic firms. They do a rotation of three months in Accident and Emergency (A\&E) unit. The A\&E rotation is done at the same time as they are doing their basic sciences. They graduate after three years with MMed. (Surgery). It is after this stage they have traditionally started their orthopaedic training.

\section{ORTHOPAEDIC TRAINING}

After MMed., the various candidates interested in orthopaedics have been attached to Kenyatta National Hospital orthopaedic unit for a minimum of one year. They have then been sent out of the country for further training. Previously they have gone to Britain, France, Germany and recently to South Africa. They got orthopaedic attachments for periods ranging between one and two years. These places and sponsorships 
have both become very scarce. SICOT has also given short stint attachments in India and Egypt. The numbers there have been small and period of training short, $3-6$ months. Training in these places has been quite varied and obviously people have come back with all sorts of papers. Some of the younger crop of orthopaedic surgeons have been trained in Uganda. This is a small number which has gone to Uganda to do M.Med Orthopaedics and on return have mostly worked in Mission Hospitals. They still have to look for opportunities to go out of the region for brief periods ranging between $3-6$ months to get further training. Some have been trained in the college system, through the College of Surgeons of East, Central and Southern Africa (COSECSA) but still this will require attachment to Kenyatta National Hospital $(\mathrm{KNH})$ and probably Moi Teaching and Referral Hospital (MT\&RH) at Eldoret. Still not enough orthopaedic surgeons will be produced. All the foregoing produce very small numbers of orthopaedic surgeons so that the provincial and district hospitals remain without properly trained orthopaedic and orthopaedic trauma surgeons. To reverse this trend the departments of orthopaedic surgery at the University of Nairobi and MT\& RH have drawn up M.Med (orthopaedic) training programmes which commenced three years ago. These are three and a half years programmes that are composed of course work, clinical practical work and a dissertation. The three and a half years look short but the university senate wouldn't allow a programme not in tandem with the other M.Med. programmes. The programmes take trainees straight from internship if they so desire on passing an entrance interview. Due to lack of any other way of selecting candidates for training, this interview has been taken as the most reliable, however, it should be noted that this is not without its shortcomings (1). The requirements for enrollment into M.Med orthopaedic programme are the candidate must be registrable with the Medical Practitioners and Dentists Board (MP\&DB); be fluent in the English language and be of sound mind. Why has there been this insistence on people in training going out of the country for a period? KNH now has quite a number of good facilities that would train an orthopaedic surgeon to fruition; however, this is still far from adequate compared to the more developed countries. The need to see how units work elsewhere and investigative facilities available is a strong incentive to send students to other more endowed countries. The detailed curricula can be found in the University of Nairobi and Moi University websites.

\section{FINANCING OF ORTHOPAEDIC TRAINING}

This being an M.Med programme, it was assumed that the government through the Ministry of Health could be the main sponsor of trainees. However, like other popular MMed programmes, the government has been very reluctant to financially sponsor students. This in essence has led to majority being self sponsored or sponsorship from other bodies other than the government. This makes the numbers coming to training rather small helping to defeat our objective of rapid training.

\section{FACILITIES AVAILABLE}

The advantage of local training can be demonstrated by looking at the situation at $\mathrm{KNH}$ which is the teaching institution for the University of Nairobi. Pathology is available in abundance. Hands on opportunities are endless. The hospital is divided into three orthopaedic firms. Each firm has operating days; clinics, ward rounds and grand rounds once a week. Operations are of all spectrum including hip and knee arthroplasties, arthroscopies, all types of operations of complex fractures, spinal surgery, but not much scoliosis, hand surgery, plastic surgery and many others. There are $X$-rays, CT scans, MRI, Isotopic scans, laboratory, radiotherapy and meager library facilities, but these have been greatly expanded by electronic library facilities. The problem is that patients have to pay separately for most of these sophisticated investigations. There is a system where residents in the United States of America (USA) come for overseas attachment at Tenwek in Bomet and Kijabe in CURE hospitals. Their home country gives special facilities that would also benefit our trainees and also provide a forum for exchange of ideas and training. $(2,3)$

\section{DISCUSSION}

The orthopaedic training in the past has had problems for the following reasons: (i) The numbers have been very small and as result provincial and district hospitals still don't have orthopaedic surgeons. (ii) The training programmes have been so varied in content and duration that end products have been very varied in competence.(iii) There has been a problem deciding on who to register as an orthopaedic surgeon. (iv) Some 
students have come back with orthopaedic diplomas which cannot even allow them to be consultants in the countries where the diplomas were awarded.

The orthopaedic training programme at the University of Nairobi was started with the view of addressing these problems. First to get enough numbers, it will be necessary to train large numbers for not a very long time. Various training programmes in the world were looked at starting with the SICOT programme (2), the Indian programme (3), Australian (4), British $(5,6)$ and South African (7) were studied. The objective was to have a programme which gives sound training without taking too long. The Indian and South African programmes appeared most attractive in content and duration. This also had to bring into focus the relevance of the curriculum content to the prevailing local situation $(8,9)$. For example it would be disastrous, as has been seen at some examinations, a student who is quite conversant with various ways of management of post arthroplasty infections yet knows little or nothing about management of acute haematogenous osteomyelitis. The same student has never done an arthroplasty. A five year programme planned for most of the surgical M.Med programmes would defeat the objective of training fast enough in the initial stages, but would be more appropriate as the numbers increase.

One of the pathways to be followed to hasten the numbers is through COSECSA. SICOT also would enhance this objective. The only problem in this regard is that the control of the training programme has been so poor that from registration of a student to completion of training has seen some students taking two years instead of five years. SICOT diploma has similarly provided some students with this shortcut. The exposure to orthopaedics in some of these shortcut situations is obviously inadequate. This is what led KOA to come up with the criteria for recognition of one as an orthopaedic surgeon and especially use of a verifiable logbook of cases done, assisted and observed.

Even with local orthopaedic training programmes it is obvious that real specialist training will take place after completion of the formal orthopaedic training. The specialist training is progressively becoming done through workshops and short intensive courses (3). Apparentship in specialised units after completion of formal training is becoming important hence the Kenyan training programme still emphasises this aspect to students.
Training in developing countries such as Kenya is also plagued by certain problems of trauma. The $\mathrm{KNH}$ has its beds in orthopaedics wards permanently filled with trauma patients. This makes it difficult to train in cold orthopaedics. There is an unsuccessful attempt to create cold orthopaedic wards, the only viable alternative at the moment is memoranda of understanding with certain mission hospitals which have cold orthopaedic units. This may only be a stop gap measure. The eventual goal is to get cold orthopaedic hospitals as happens in other more developed countries and the government support on this matter is very important. Teaching hospitals are administered by administrators purely interested in service provision, and this does not help matters.

Another problem to be addressed by Kenyan orthopaedic training programmes is provision of up to date investigative procedures and personnel. There is no point in having an up to date MRI machines yet personnel to interpret are lacking. Orthopaedic oncology will also be another area to be tackled, either by importation of short term trainers or send abroad interested pathologist so that in the long run these experts become locally available. The part of short term visiting lecturers in certain specialised fields is being pursued with a number of international bodies such as the British Orthopaedic Association. These include six months to one year visits by paediatric, orthopaedic, scoliotic, hand and feet surgeons and many more. There is also need to pay attention to the training of trainers as sometimes too much attention is placed on trainees yet the problem is at the trainers level $(9,10)$. All the training institutions should make research mandatory and this be recognised and rewarded appropriately $(8,9,10)$. This will help develop priorities in the local environment thus show areas where more energy will need to be directed.

There is need to look at the sponsorship of trainees as orthopaedics is one area where there is still great need to rapidly train and fill vacancies in the provincial and district hospitals. There is also a danger that those who can afford to sponsor themselves may not necessarily be the best candidates. An automatic loan system to cater for these candidates who have succeeded at the interviews and release from their places of work will be great help to enhance our training objective. The government indulgence will be a great help. 


\section{CONCLUSION}

It can be said that orthopaedic training in the past has been inadequate in quantity and quality. A good start has been made by starting of the two programmes at University of Nairobi and MT\&RH in Eldoret. These two will not achieve the ultimate objectives without injection of resources from well established institutions in form of material, facilities and personnel. The government will also come in strongly to assist the institutions with creation of cold orthopaedic units separate from the overcrowded trauma units. Supporting bodies in training will have to be monitored carefully to avoid shortcuts previously seen in the training. The registration criteria for specialists will have to be meticulously followed by the Medical Practitioners and Dentists Board. Training of the trainers and other specialised support personnel will have to be pursued with vigour.

\section{REFERENCES}

1. Bernstein, A.D., Jazrawi, L.M., Elbeshbeshy, B., et al. Orthopaedic resident selection criteria. J. Bone J. Surg. 2002; 84(A): 2090 - 2096.

2. SІСОT. Education and training. Sicot training manual. http://www.sicot.org|?id
3. Jain, A.K. Orthopaedic services and training at a crossroad in developing countries. Ind. J. Ortho. 2007; 41: 177 179.

4. Specialist training in orthopaedic Surgery in Australia. http://tpgsite.aoa.org.au|training.asp

5. Welsh orthopaedic training programme. http://welshortho. co.uk/

6. Tom, A.D., Mcleland, D. and Maffulli, N. Trauma and Orthopaedic Training in the United Kingdom. J. Bone J. Surg. 2002; 84(A): 501 - 503.

7. Dormans, J.P. Orthopaedic surgery in developing world -can orthopaedic residents help? J. Bone J. Surg. 2002; 84(A): $1086-1094$.

8. Kurup, N.V. and Sarasin, S. Orthopaedic training world wide: how they compare? A pilot study. Arch. Ortho. Trauma. 2009; 129: 625 - 629.

9. Samiento, A. The education of future orthopaedists. A need for improvement. J. Bone J. Surg. 2001; 83(A): 1427.

10. Jackson, D.W. The orthopaedic clinician - scientist. J. Bone J. Surg. 2001; 83(A): 131 - 135. 